\title{
Mesoporous Silica Nanoparticles in Nanomedicine applications.
}

\author{
Miguel Manzano ${ }^{\mathrm{a}, \mathrm{b}}$ and María Vallet-Regi ${ }^{\mathrm{a}, \mathrm{b}}$ * \\ ${ }^{a}$ Dept. Che mistry in Pharmaceutical Sciences, School of Pharmacy, Universidad Complutense de Madrid, Instituto de \\ Investigación Sanitaria Hospital 12 de Octubre i+12, Plaza Ramón y Cajal s/n, E-28040 Madrid, Spain. \\ ${ }^{b}$ Networking Research Center on Bioengineering, Biomaterials and Nanomedicine (CIBER-BBN), Madrid, Spain. \\ E-mail:vallet@ucm.es; Fax: +34913941786; Tel: +34913941861.
}

\begin{abstract}
In the last few years Mesoporous Silica Nanoparticles (MSNs) have gained the attention of the nanomedicine research community, especially for the potential treatment of cancer. Although this topic has been reviewed before, periodic updates on such a hot topic are necessary due to the dynamic character of this field. The reasons that make MSNs so attractive for designing controlled drug delivery systems lie beneath their physico-chemical stability, easy functionalisation, low toxicity and their great loading capacity of many different types of therapeutic agents. The present brief overview tries to cover some of the recent findings on stimuli-responsive mesoporous silica nanocarriers together with the efforts to design targeted nanosystems using that platform. The versatility of those smart nanocarriers has promoted them as very promising candidates to be used in the clinic in the near future to overcome some of the pitfalls of conventional medicine.
\end{abstract}

\section{Graphical Abstract}

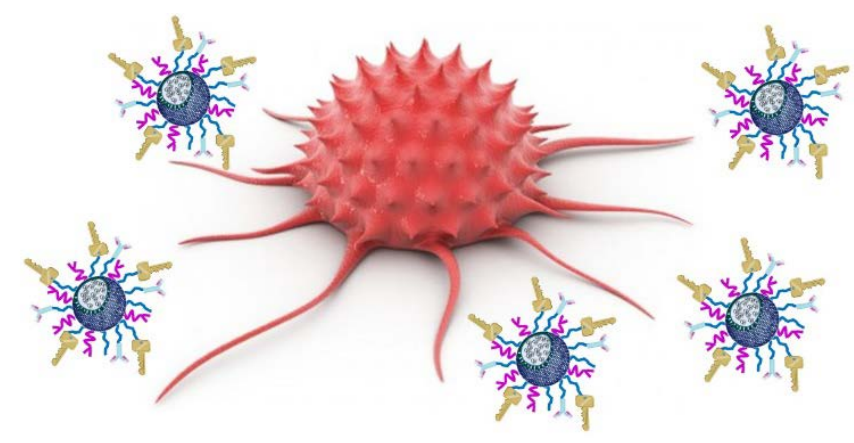

\section{Introduction}

Recent advances in Nanotechnology have provided a totally new arsenal to modern medicine in the last few years, giving birth to the so-called Nanomedicine [1,2]. This new biomedical area is inspiring more specific and efficient treatments towards complex diseases such as cancer [3]. Among that new armoury, nanoparticles for drug delivery can be employed for the treatment of the disease through the transport and release of therapeutic agents on a controlled manner, overcoming some of the typical limitations of systemic treatments. Nanoparticles acting as delivery vehicles of different pharmaceutical agents are predominant within nanomedicine, representing about the $75 \%$ of the market share of approved nanomedicines [4]. Some of the advantadges of using nanopartciles for drug delivery include the pharmacokinetic profile improve, the capacity to release therapeutic agents to specific 
tissues decreasing the side effects, and in some cases the capability to overcome certain biological barriers. Additionally, nanoparticles have been also used in other areas of nanomedicine, such as in: diagnosis, where nanopartciles allow to gain a better sensibility and precision; theragnostic, which is based on the combination of therapy and diagnosis and allows the detection and localised therapy of certain diseases together with the possibility of following the treatment on real time; and included in nanodevices, which can be used as biosensors and nanorobots.

There are many different nanoparticles that have been proposed as nanomedicines, and probably the most popular are liposomes and lipid-based nanomedicines, protein nanoparticles, polymeric micelles and nanoparticles, polymer-drug conjugates and diverse inorganic nanoparticles. Among the last, Mesoporous Silica Nanoparticles (MSNs) have been deeply investigated as drug delivery nanocarriers because of their physico-chemical properties $[5,6,7,8]$. Those MSNs are very robust, which means that they are mechanically, thermally and chemically stable. They provide a great loading capacity within the porous system [9] thanks to their outstanding properties for the adsorption of many different types of molecules, such as high surface area (ca. $1000 \mathrm{~m}^{2} / \mathrm{g}$ ), high pore volume $\left(c a .1 \mathrm{~cm}^{3} / \mathrm{g}\right)$ and narrow distribution of tunable pore diameters $(2-30 \mathrm{~nm})$, as it can be observed in Figure 1. Thanks to those properties, MSNs have been employed as drug delivery systems [10], as nanosystems for diagnosis [11] and nanosystems for gene transfection [12].
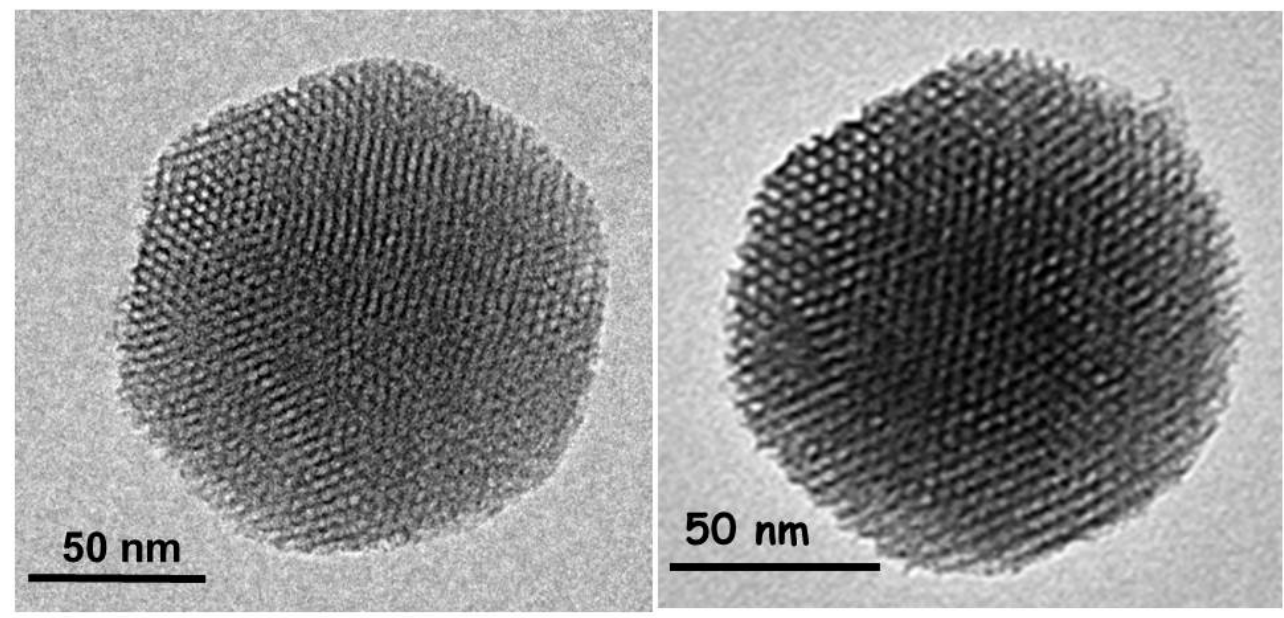

Figure 1. Transmission Electron Microscopy (TEM) images of MCM41 type MSNs where the network of mesoporous cavities available for drug loading can be observed.[7]

Additionally, the surface of MSNs is very easy to chemically modify thanks to the silanol groups present on their surface, which allows designing multifunctional platforms with many different characteristics.

All those features of MSNs have inspired many different research groups to host different therapeutic agents for transporting them to the tissue if interest $[13,14,15]$. MSNs have been observed to be endocytosed by many different mammalian cell lines $[16,17,18,19]$ and the in vitro toxicology experiments have shown that MSNs are well tolerated at dosages lower than $100 \mu \mathrm{g} / \mathrm{mL}$ [20]. Additionally, in vivo biocompatibility studies of MSNs on different animal models have demonstrated that are well tolerated at dosages lower than $200 \mathrm{mg} / \mathrm{Kg}$ [21]. As those MSNs would be administered through intravenous injection to the bloodstream, the hemocompatibility has also been deeply investigated, showing positive results $[22,23]$. 
The state of the art of this first generation of MSNs with biomedical applications has been reviewed somewhere else.[24] However, the second generation of MSNs should be successfully translated from the pre-clinical proof of concept to the clinic through the demonstration of therapeutic value. For that purpose, the efficacy and lack of toxicity should be clearly presented through the appropriated pharmacokinetic and pharmacodynamics evaluations, together with biodistribution studies before immersing into clinical trials.

The synthesis of MSNs is based on a modification of the Stöber method in which the sol-gel process is employed under very dilute conditions to obtain nanoparticles. During this synthetic procedure, surfactants are used as structure directing agents, so the silica precursors would condensate over those templates. Then, in a final step, removing the surfactant would lead to the network of cavities typical of these mesoporous materials.

As it has been commented above, most of nanoparticles for drug delivery have been designed for the treatment of complex diseases such as cancer. In this sense, when considering the potential treatment of cancer, the use of nanoparticles loaded with therapeutic agents requires to those nanocarriers reaching the disease site and releasing the drugs there. In general, the drug delivery process to a solid tumour consists of 5 main steps, which are known as the CAPIR cascade: circulation in blood, accumulation and penetration into tumours, cellular internalisation, and intracellular release [25].

Long circulation time in blood can be achieved through several ways, such as their size (ca. $100 \mathrm{~nm}$ so they will not slip out of the blood vessels during their journey into the body), or appropriate surface functionalisation to avoid interactions with blood components and reticuloendothelial system (RES). Tumour targeting can be achieved through the surface modification of nanoparticles, in which MSNs are virtually unbeatable in comparison to other nanocarriers. The reason for that is that MSNs allows carrying many different grafting reactions using different organic solvents, at relatively high temperatures and using multiple organosilanes functionalising agents. Regarding cellular internalisation and intracellular release, MSNs have been observed to penetrate into many different types of cells (Figure 2), especially when their surface is positively charged [26].

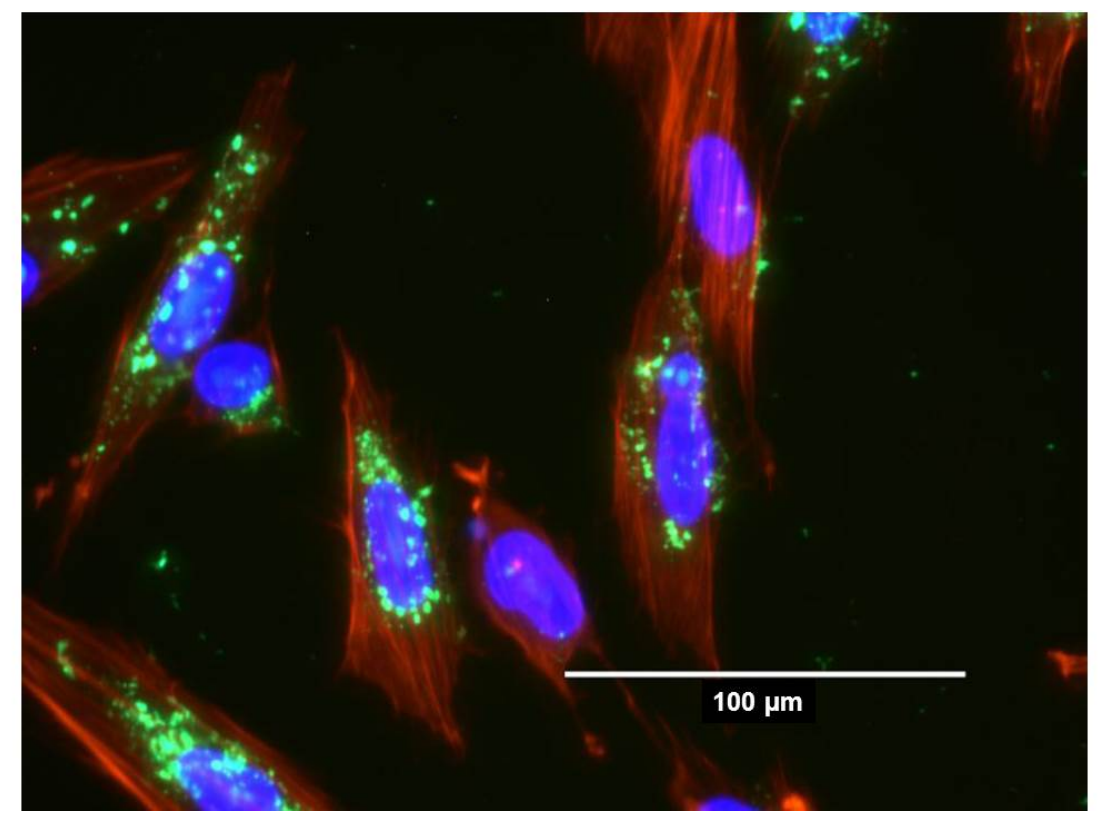

Figure 2. MSNs (labelled in green) internalised into mesenchymal stem cells.[26] 
Thus, the actual challenge of MSNs, and nanomedicines in general, is the selectivity towards certain targets into the body. The reason for that is due to the fact that conventional drugs rarely discriminate between healthy and cancerous cells. A possible way to overtake this pitfall consists on loading nanoparticles with those drugs to stay longer in circulation and accumulate in tumours rather than in healthy tissues. The way that those nanoparticles can target those tumour tissues would be discussed later in this review.

This paper aims to review the latest findings on MSNs as drug delivery nanocarriers within the existing literature, and showing some of the results obtained by our research group in the last few years. The importance of this review may be derived from the rapidly evolving field of nanomedicine, in which the number of publications regarding MSNs as stimuliresponsive drug delivery systems is constantly increasing, as shown in Figure 3. Thus, even though there are already many reviews on MSNs for drug delivery in the literature, this is such a dynamic field and things might change so fast, that regular updates are necessary to keep the audience informed on the last findings in the field. Thus, the present review is focused on the latest advances on MSNs as drug delivery agents, highlighting the development of responsive and targeted nanocarriers.

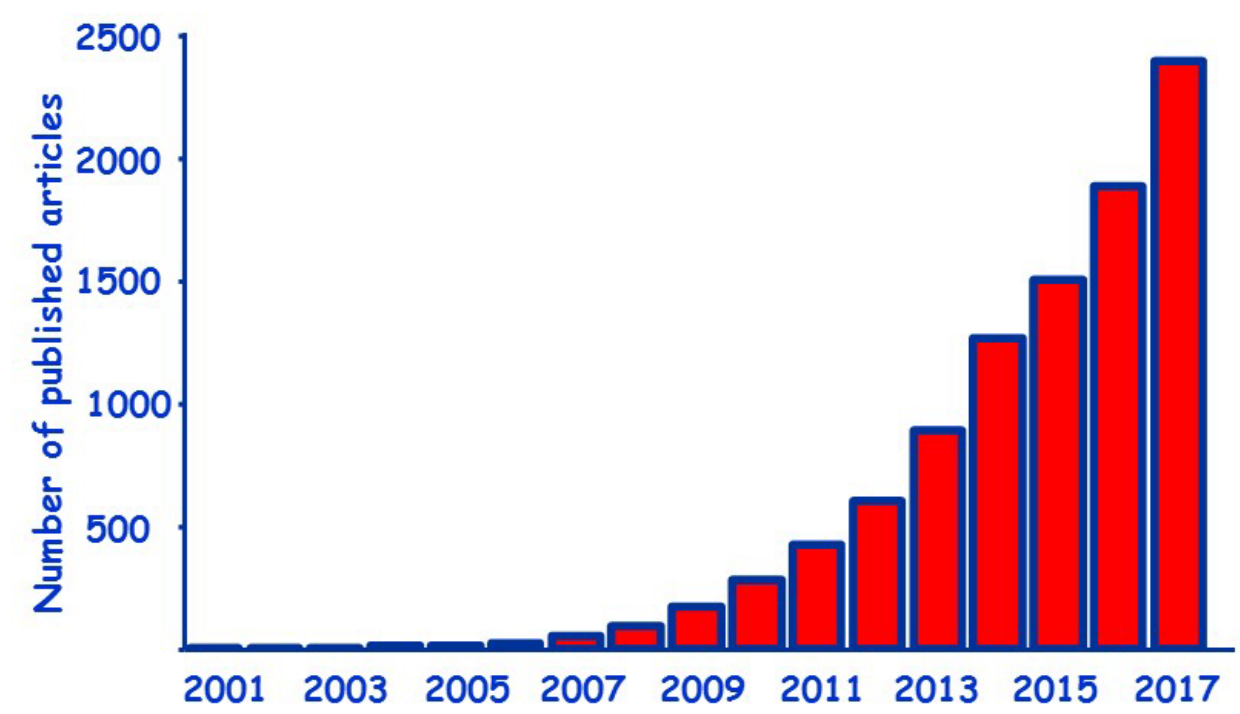

Figure 3. Evolution of the publication of research a rticles on Responsive-MSNs for drug delivery. Da ta obtained from Google Scholar.

\section{Stimuli-Responsive MSNs}

MSNs present open porosity, which means that it might be possible to introduce therapeutic agents into their network of cavities, but it also might be possible for those agents to diffuse out when they might be in solution, obviously depending on the solvent and the selected drug. Therefore, it is necessary to close the pore entrances to avoid the premature release of the cargo during their journey through the blood vessels, which could cause several side effects due to the unspecific release of the drugs (Figure 4). 


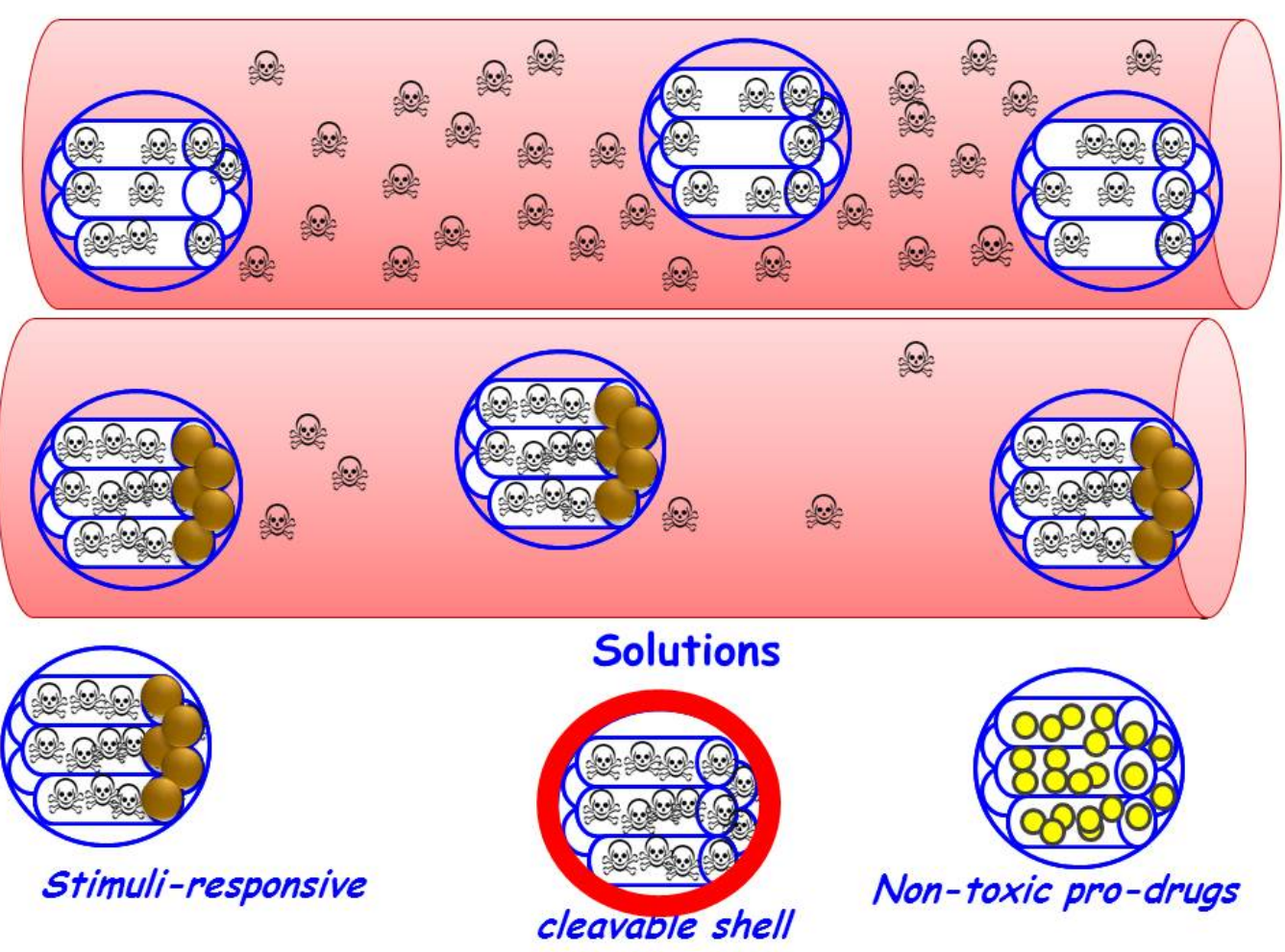

Figure 4. Schematic re presentation of the unspecific release of MSNs cargo (top) and the potential solutions to avoid it (bottom).

The task of closing the pore entrances can be approached from different perspectives, and probably the most common is grafting stimulus sensitive gates to the pore entrances or covering the whole nanoparticle with a cleavable shell that would allow triggering the release when detached. In both cases, the final outcome would be the pore entrance closure that could be opened under the action of certain stimuli, both internal, which are typical from the treated pathology and include $\mathrm{pH}$, redox potential and enzymes concentration among others; or external, that can be remotely applied by the clinician and include magnetic fields, ultrasounds, electrical fields or light (Figure 5). Previous reviews have focused on stimulusresponsive mesoporous silica, both bulk and nanoparticles, with gate-like assemblies on pore openings.[27] 


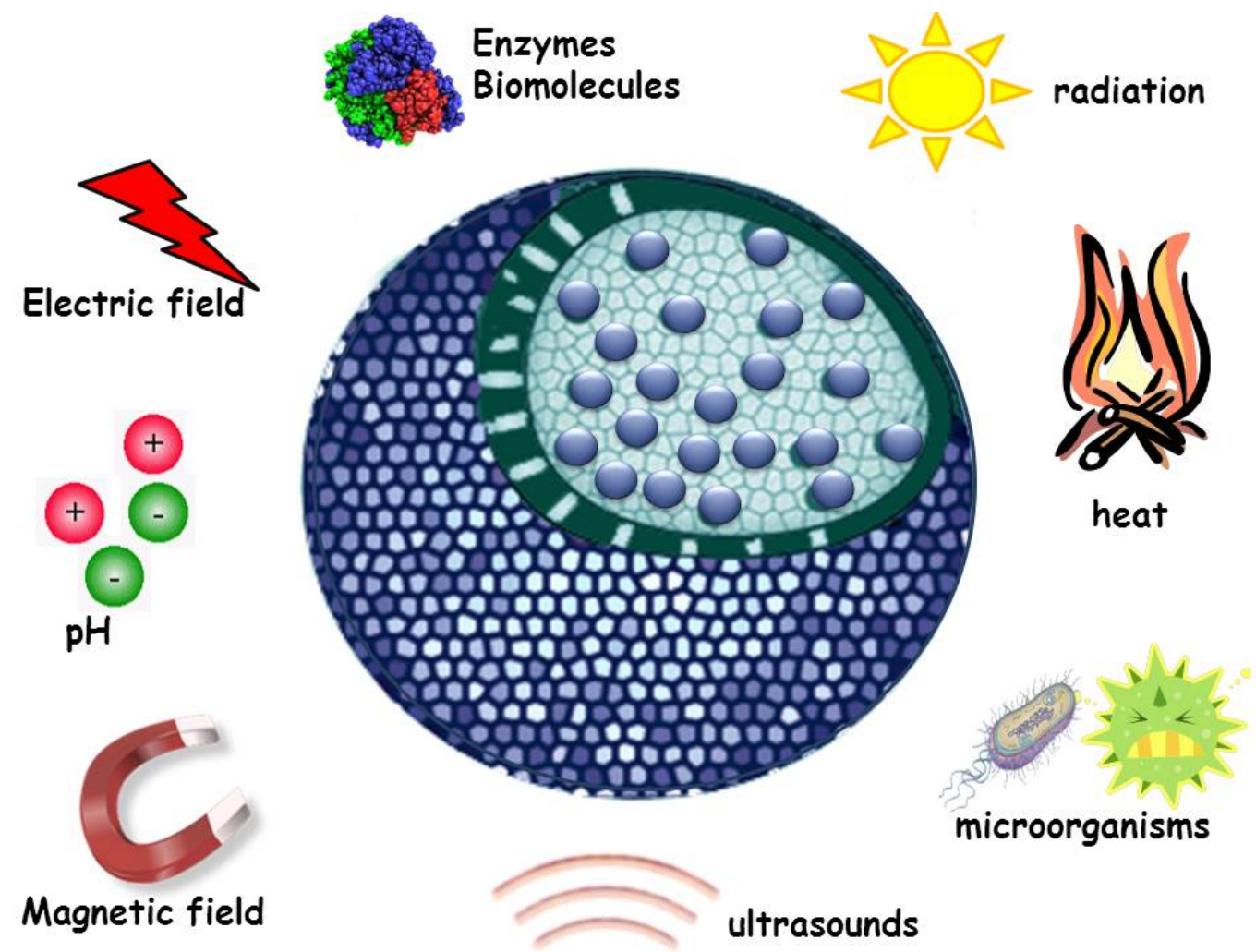

Figure 5. Schematic re presentation of a ca pped MSN and the different stimuli, both internal and external, that can trigger the release of the cargo.

\section{Magnetic fields responsive MSNs}

Magnetic fields are one of the most employed stimuli in nanomedicine because they can be used to magnetically guide the nanoparticles when using a permanent magnetic field or to locally increase the internal temperature when using an alternating magnetic field. In this sense, superparamagnetic microspheres with an $\mathrm{Fe}_{3} \mathrm{O}_{4} @ \mathrm{SiO}_{2}$ core and a mesoporous silica shell were produced with magnetisation and large pore volume, with great promise to be used as magnetically controlled drug delivery systems.[28] A similar approach was followed to fabricate spheres with a uniform particle diameter of $c a .270 \mathrm{~nm}$ with a core of magnetic $\mathrm{Fe}_{3} \mathrm{O}_{4} / \mathrm{Fe}$ and a mesoporous silica shell able to encapsulate Ibuprofen. [29] Regarding their use with MSNs, the most popular strategy consists on incorporating superparamagnetic iron oxide nanoparticles (SPIONs) of ca. 5-10 nm encapsulated within MSNs network during their synthesis [30,31]. Thus, the application of an alternating magnetic field to the system would increase the local temperature, so if the pore entrances were previously closed with a temperature responsive moiety, the release of the cargo would be triggered. This behaviour was achieved encapsulating iron oxide small nanoparticles into the network of MSNs and covering the surface of those MSNs with a thermosensitive polymer, poly $(\mathrm{N}-$ isopropylacrylamide), to close the pore entrances to retain the cargo inside avoiding premature release. Additionally, a polyamine was added to the thermoresponsive polymer to be able to retain proteins within the shell of the nanoparticles (Figure 6). That way, it was possible to release two types of agents at the same time: the drug encapsulated into the pores (fluorescein was used as model molecule) and the protein retained into the shell (trypsin inhibitor was used as model protein) [32]. 

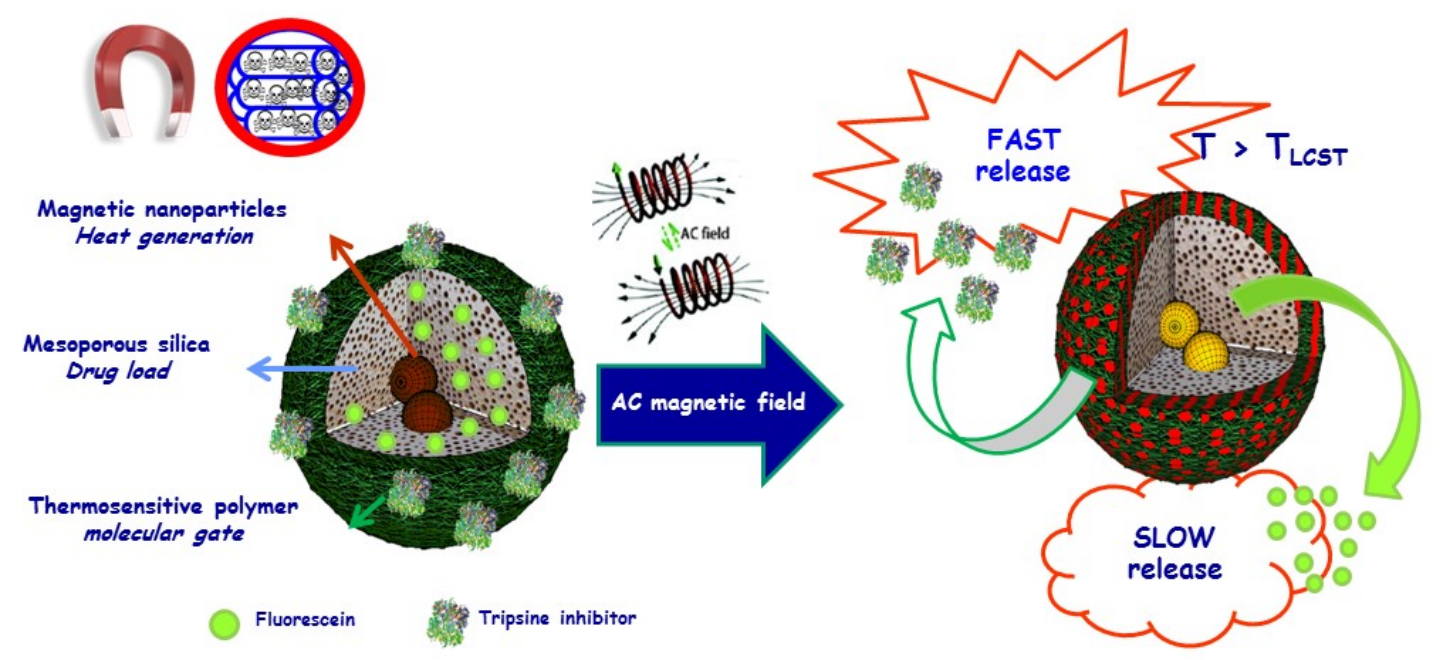

Trypsin inhibitor release: fast release
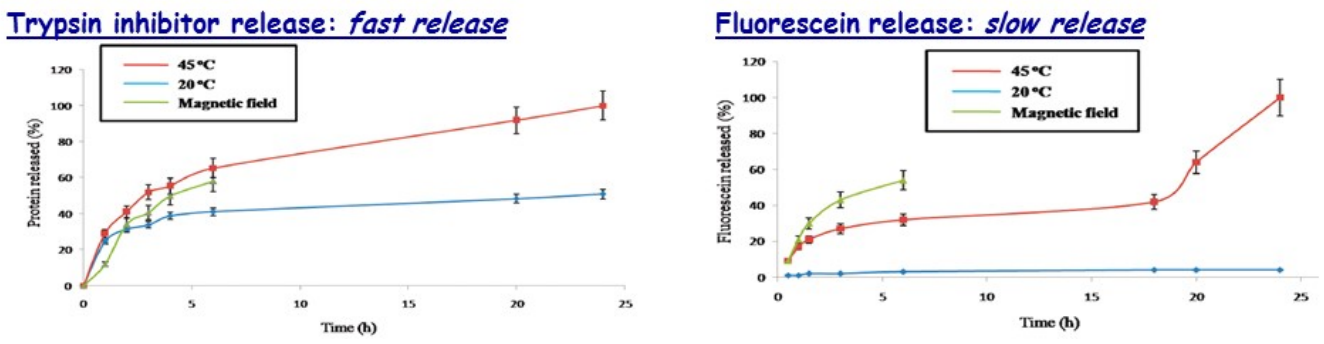

Figure 6. Schematic representation of a magnetic responsive MSNs able to release two types of agents: small molecules encapsulatedinto the pores and large proteins retained within the shell of the nanoparticles.[32]

As it can be observed in Figure 6, when applying an alternating magnetic field, the iron oxide nanoparticles increased the local temperature up to a point at which the conformation of the thermoresponsive polymer changed, so the pore entrances were opened and the protein and small molecules cargoes were released following different kinetics.

Another proof of concept of this type of responsive materials consisted on functionalising MSNs with a single DNA strand and then loading the cargo inside the pores [33]. Separately, the complementary DNA sequence was attached to magnetic iron oxide nanoparticles of $c a .5 \mathrm{~nm}$ of diameter. Then, both MSNs and DNA-iron oxide nanoparticles were mixed to allow DNA hybridisation, as it can be observed in Figure 7. 


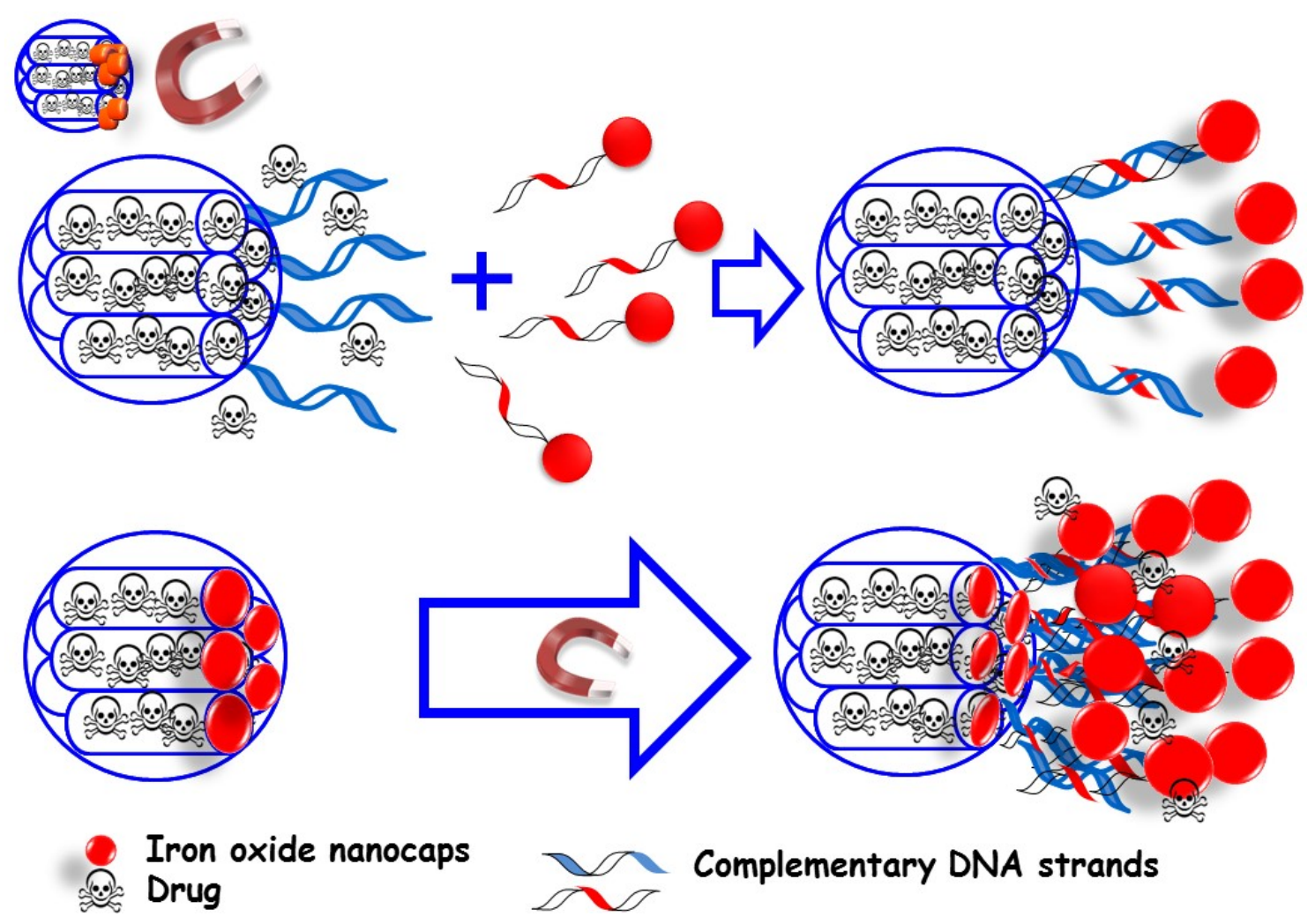

Figure 7. Schematic representation of the proof of concept MSNs responsive to magnetic fields using DNA complementary strands to block the pore entrances.[33]

The DNA sequence employed was selected because it presents a melting temperature of $47^{\circ} \mathrm{C}$, so once the system was exposed to an alternating magnetic field, the iron oxide nanoparticles encapsulated into the MSNs network were able to increase the local temperature. Thisled to the double-stranded DNA melting with the subsequent pore aperture and cargo release. One of the interesting aspects of this proof of concept is that DNA linkage is reversible, so when the magnetic field is switched off and the system might reach physiological temperature, the DNA strands would hybridise again closing the pores. Then, they could be opened and closed again, leading to a pulsatile or on-off release mechanism.

Same type of superparamagnetic iron oxide nanocaps have been employed in mesoporous silica nanorods in which the cell-produced antioxidants trigger the release of the cargo in the presence of an external magnetic field.[34]

\section{Light responsive MSNs}

The use of light with different wavelengths (ultraviolet, visible or near-infrared) for triggering the cargo release from MSNs has become very popular in the last few years. Some of the benefits of using light to trigger the release from MSNs is its easy application by the clinician and the focalisation to the targeted tissue, although the tissue penetrability is only few centimetres. Among all the possibilities, UV has been the most popular type of radiation to stimulate the cargo release from MSNs, because its high power is able to break bonds [35]. A proof of concept using this technology is presented in Figure 8, where MSNs were covered with a protein shell using a photosensitive linker that could be cleaved under light radiation at $366 \mathrm{~nm}$ [36]. The shell covering the nanoparticles was also functionalised with transferrin, because it is well known that cancer cells overexpress receptors for that ligand. Thus, once the MSNs might be internalised into the tumour cells, the application of UV light would trigger the 
drug release, making this approach suitable for treating tumours that are accessible for light irradiation like the case of melanomas.

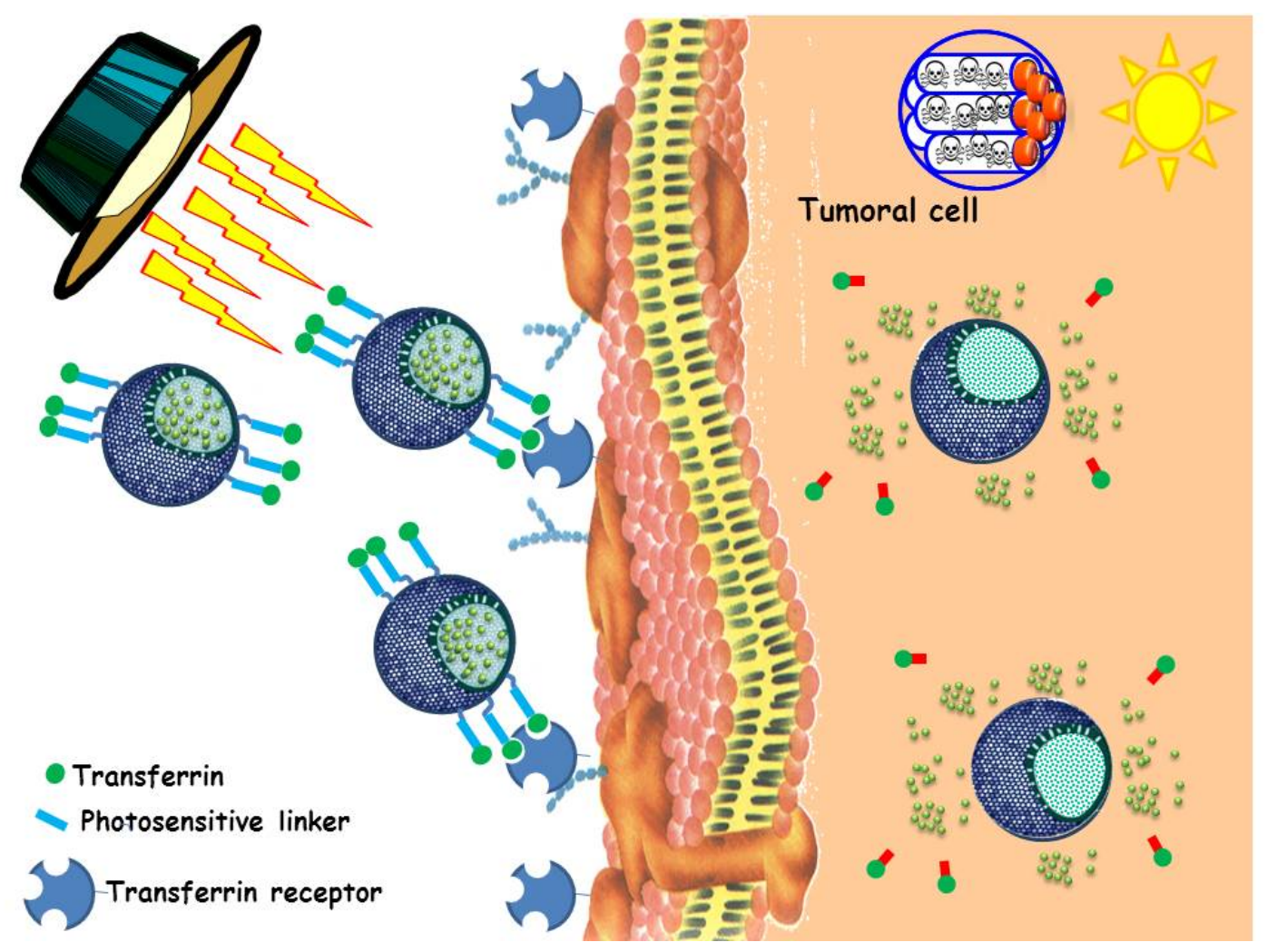

Figure 8. Sche matic re presentation of MSNs sensitive to UV Iight: the nanoparticles present high affinity towa rds tumour cells and once in the cytoplasm, the application of UV light trigger the cargo of the MSNs.[36]

However, UV light might be toxic because of its high Energy and also presents low penetration capacity. A possible alternative could be the use of visible light because it is safer and present higher tissue penetrability. In fact, a proof of concept of a visible light triggered MSNs release system has recently been published [37].

\section{Ultrasound sensitive MSNs}

Ultrasound (US) is a very interesting stimuli to be used in nanomedicines because it can penetrate deep into living tissues without causing damage. Additionally, US is non-invasive and it can be focalised. Our research group has developed an US sensitive MSNs drug delivery system that can be activated using an US equipment that is normally used in the rehabilitation clinics. That system is based on decorating the surface of MSNs with a copolymer made of a thermosensitive and US sensitive components to close the pore entrances avoiding the premature release of the cargo [38]. Under the application of US, certain part of the copolymer cleaves, changing the hydrophobicity of the copolymer. This leads to a change of the conformation of the polymer at physiological temperature, opening the gates of the MSNs and triggering the release of the cargo, as it can be observed in Figure 9. 

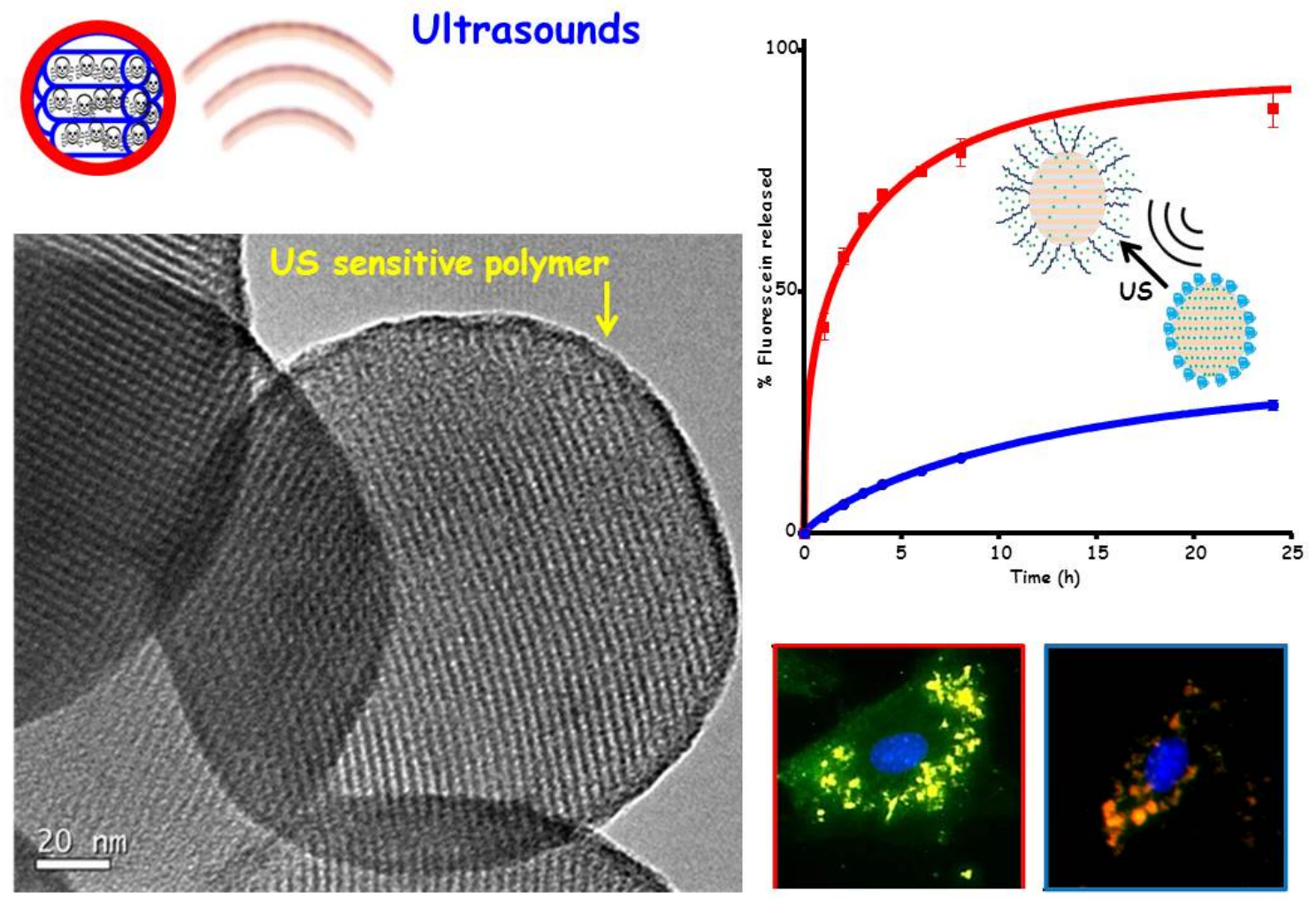

Figure 9. Schematic representation of the US sensitive MSNs carriers including a TEM micrograph of the MSNs decora ted with the copolymer, the in vial release kinetics, and the cell internalisation and in tracellular release of the cargo.[38]

In a similar approach, mesoporous silica nanoparticles have been employed to develop transdermal drug delivery systems that could simultaneously sense temperature and US stimuli.[39] The MSNs were decorated with a US sensitive polymer following the same procedure as the above described by our research group.

Ultrasound has also been proven to be very useful guiding and imaging Au nanoparticles-coated, perfluorohexane-encapsulated and PEGylated mesoporous silica nanoparticles.[40] In this approach, US irradiation effectively triggered drug release and excited contrast-intensified ultrasound imaging and increase ablation efficacy thanks to the US guidance.

\section{pH sensitive MSNs}

Regarding internal stimuli, which are those that employ the characteristics of the pathology to be treated, $\mathrm{pH}$ is one of the most employed to trigger the drug release from nanomedicines because in most tumours the $\mathrm{pH}$ is lower than in healthy tissues. The reason for that difference is the high rate of glycolysis in cancer cells, which leads to a high production of lactic acid and to a reduction in the $\mathrm{pH}$. That different $\mathrm{pH}$ has inspired many different approaches based on blocking the pore entrances of MSNs with different moieties that are grafted to the surface of the nanoparticles through responsive linkers, such as acetal linkers [41], boronate ester [42], ferrocenyl linkers [43], different polymers [44], aromatic amines [45], imine bonds [46], or calcium phosphates that are soluble at acid pH's [47]. Our research group has recently developed a pH responsive MSNs based system to transport and deliver topotecan, a potent cytotoxic agent that commonly degrades at physiological $\mathrm{pH}$, which limits its clinical use [48]. The surface of the topotecan loaded MSNs was decorated with a gelatin that was sensitive to 
acid $\mathrm{pH}$, and then Folic Acid moieties were added to the external surface to direct the nanocarriers towards tumour cells that overexpress folic acid receptors (Figure 10).

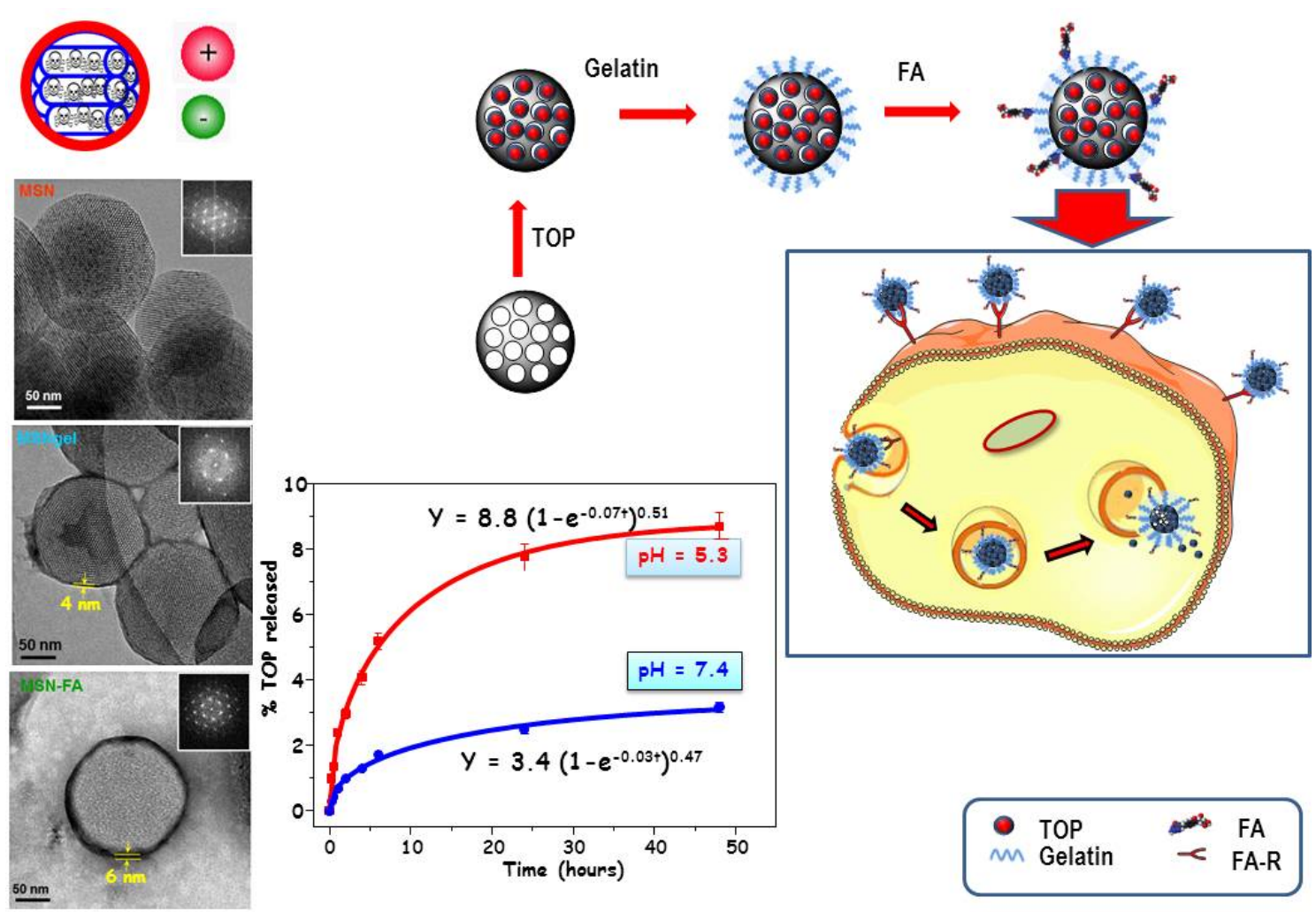

Figure 10. Schematic representation of $\mathrm{pH}$ sensitive MSNs prepared using a $\mathrm{pH}$ sensitive gelatin (top), TEM micrographs of the as produced systems (left) and in vial release kinetics under different pHs.[48]

Another proof of concept of MSNs sensitive to $\mathrm{pH}$ changes has been developed employing Self-Immolative Polymers (SIPS) to decorate the external surface of the nanoparticles [49]. The employed SIPs consist of a linear polymer based on a polyurethane chain with a molecule sensitive to acid pH at one of the ends. Once that molecule is cleaved because of acid $\mathrm{pH}$, the disassembly of the polymer from head to tail would be triggered, yielding the initial monomers, in a process known as self-immolation. MSNs loaded with a model molecule were decorated with the SIP that at physiological $\mathrm{pH}$ was stable, so premature release on heal thy tissues would be avoided. However, when the SIP coated MSNs system was exposed to acid $\mathrm{pH}$, the trigger initiated the disassembly of the polymer, which provoked the aperture of the pore entrances and, therefore, triggering the release of the cargo only in acidic environments, as it can be observed in Figure 11. 


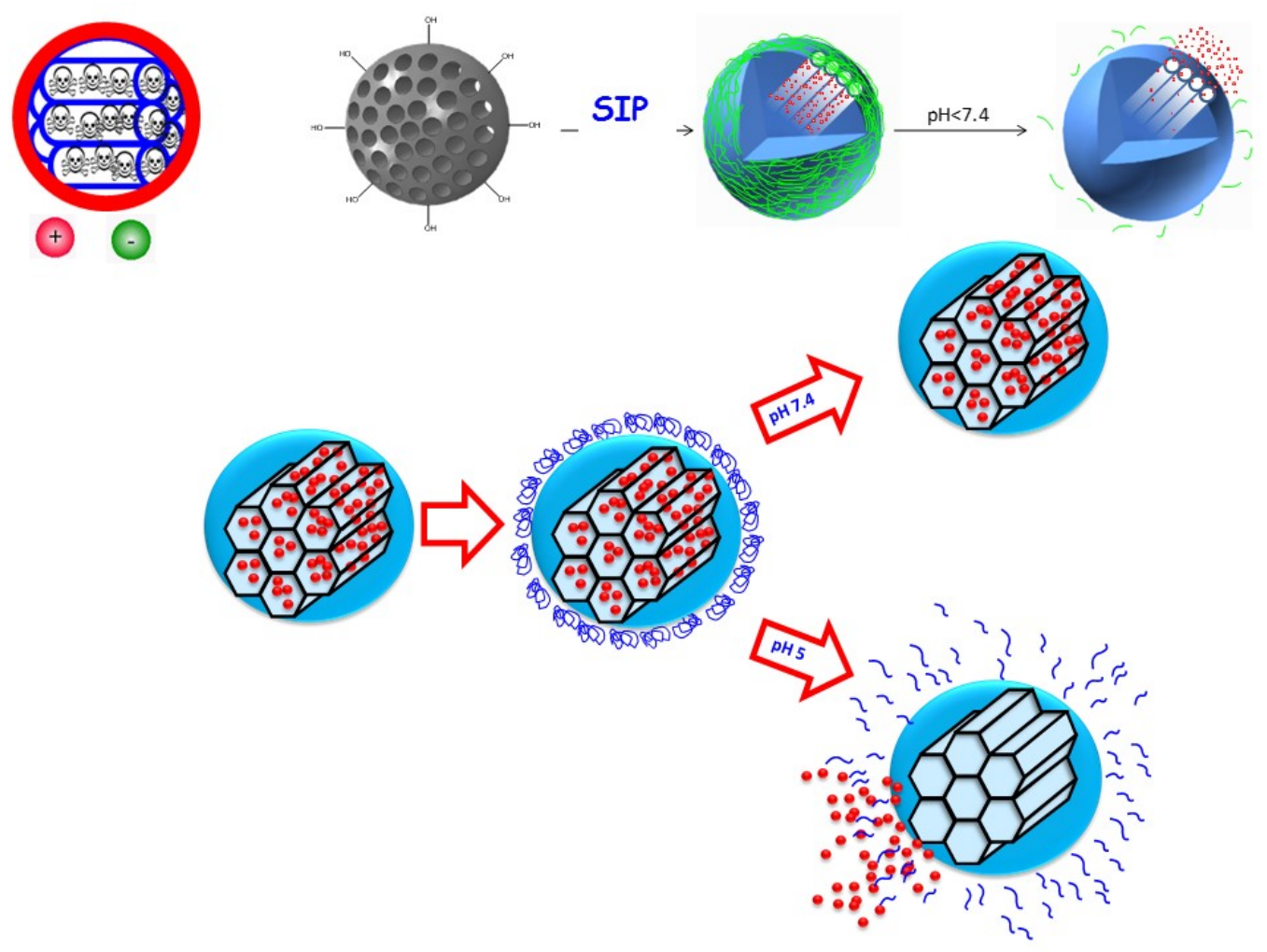

Figure 11. Schematic representation of the SIP-MSNs system sensitive to acid pH.[49]

Poly(acrylic acid), which is known to be $\mathrm{pH}$ responsive, has also been employed to decorate the surface of mesoporous silica nanoparticles.[50] The release of Doxorubicin from this platform was observed to be $\mathrm{pH}$ dependant, and it also increased with the decrease of the $\mathrm{pH}$. Polymer shells composed of acrylamide and methacrylic acid coating mesoporous silica nanoparticles have been also employed for the design of thermo and $\mathrm{pH}$ dual responsive systems for controlled drug release.[51]

Nanovalves sensitive to $\mathrm{pH}$ have been employed for controlling the delivery of certain antibiotics from mesoporous silica nanoparticles, and their efficacy in treating some infections has been demonstrated.[52] This was an interesting approach because most of research on MSNs for drug delivery has been devoted to potential cancer treatment, with very few papers focused on the treatment of infectious diseases. This al most unexplored application might be fuelled up by the fact that some infectious diseases caused by pathogens reside within macrophages, which internalise nanoparticles more efficiently than other cells, which might help increasing efficacy and reducing systemic toxicity.

\section{MSNs loaded with prodrugs}

When considering nanoparticles for drug delivery for the potential treatment of cancer, the transported cargo is normally a highly cytotoxic drug, so premature release before reaching the tumour tissue should be avoided at all costs. This is the main motivation of stimuliresponsive systems, but it is very difficult to design systems that do not release any of their cargo before reaching the target site, that is, zero-release systems, as it has been shown in previous examples. A possible alternative could be the use of nanocarriers able to transport the cytotoxic agents in an inactive state and, once they might reach the tumour tissue, activate those agents so the highly toxic compounds would be generated only in the targeted tissue. This approach has been developed employing nanoparticles able to transport a prodrug that 
would be activated by certain enzymes overexpressed by the tumour tissue [53]. However, this strategy is limited by the low concentration of activating enzymes in the tumour or even by the lack of naturally occurring enzymes necessary to activate certain prodrugs.

MSNs have been employed to develop a system able to in situ generate cytotoxic drugs within tumour cells transporting both the non-toxic prodrug, loaded in the pore network, and the enzyme required for the drug activation, grafted to the surface of the MSNs [54]. The encapsulated prodrug was indol-3-acetic acid and the enzyme grafted the surface of MSNs was horseradish peroxidase, that is able to transform indol-3-acetic acid into indole-3carbinol generating cytotoxic compounds such as hydroxyl and reactive oxygen species. The stability of the enzyme was ensured by coating them with a polymeric capsule (Figure 12).

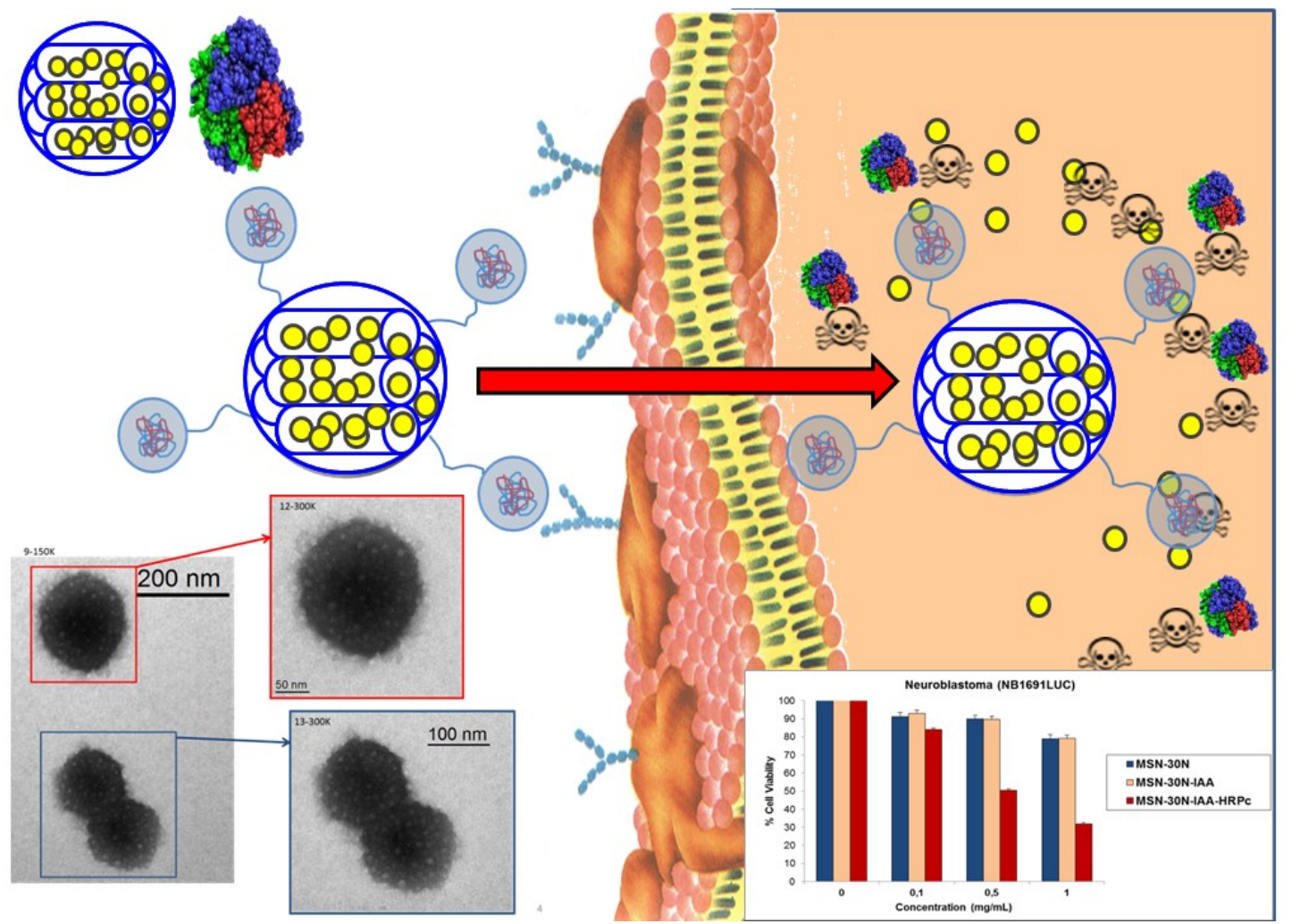

Figure 12. Schematic re presentation of MSN loaded with a prodrug and decorated with encapsula ted enzymes on the ir s urface. Indol-3-acetic a cid is released a nd a ctivated intracellularly by the horseradish peroxi dase lea ding to the production of cytotoxic compounds to provoke cancer cells death.[54]

Cisplatin was the first platinum-based anticancer drug and was proven to be one of the most potent anticancer drugs. However, its efficacy has been reduced by resistance of cancer cells. The use of nanocarriers able to internalise and ensure intracellular cisplatin accumulation results in an innovative and promising strategy to circumvent cisplatin resistance. In this sense, MSNs have been employed to deliver a cisplatin prodrug, together with chlorin e6, for the design of a combination of chemophotodynamic dual therapy against cisplatin resistant cancer cells.[55]

\section{Selective targeting for MSNs}

Localising nanocarriers into the specific tissues where the therapeutic agent is required is one of the milestones when considering MSNs for nanomedicine. That is of particular interest if nanocarriers are going to be used in cancer therapies to avoid side effects and damage to 
healthy cells. In fact, cancer is the pathology that is receiving most of the attention from the nanomedicine community, and the reason for that is the possibility of targeting the nanocarriers to specific tissues, both through passive and/or active targeting.

When MSNs, and nanoparticles in general, are injected into the blood stream, they tend to accumulate in solid tumours thanks to the so-called enhanced permeation and retention (EPR) effect or passive targeting $[56,57]$. The reason for that lies beneath the abnormalities present in tumour blood vessels, that present wide interendothelial junctions, a great amount of phenestrations and transendothelial pores with dimensions of several hundred $\mathrm{nm}$ (Figure 13). Thus, when nanoparticles are travelling through the bloodstream, there is a high probability that they might extravasate through the previously mentioned fenestrations present in tumour vessels and accumulate into the tumour interstitium. Additionally, those nanoparticles al ready in the tumour would remain in there because of the ineffective lymphatic drainage that results from the fast growth of the tumour tissue.

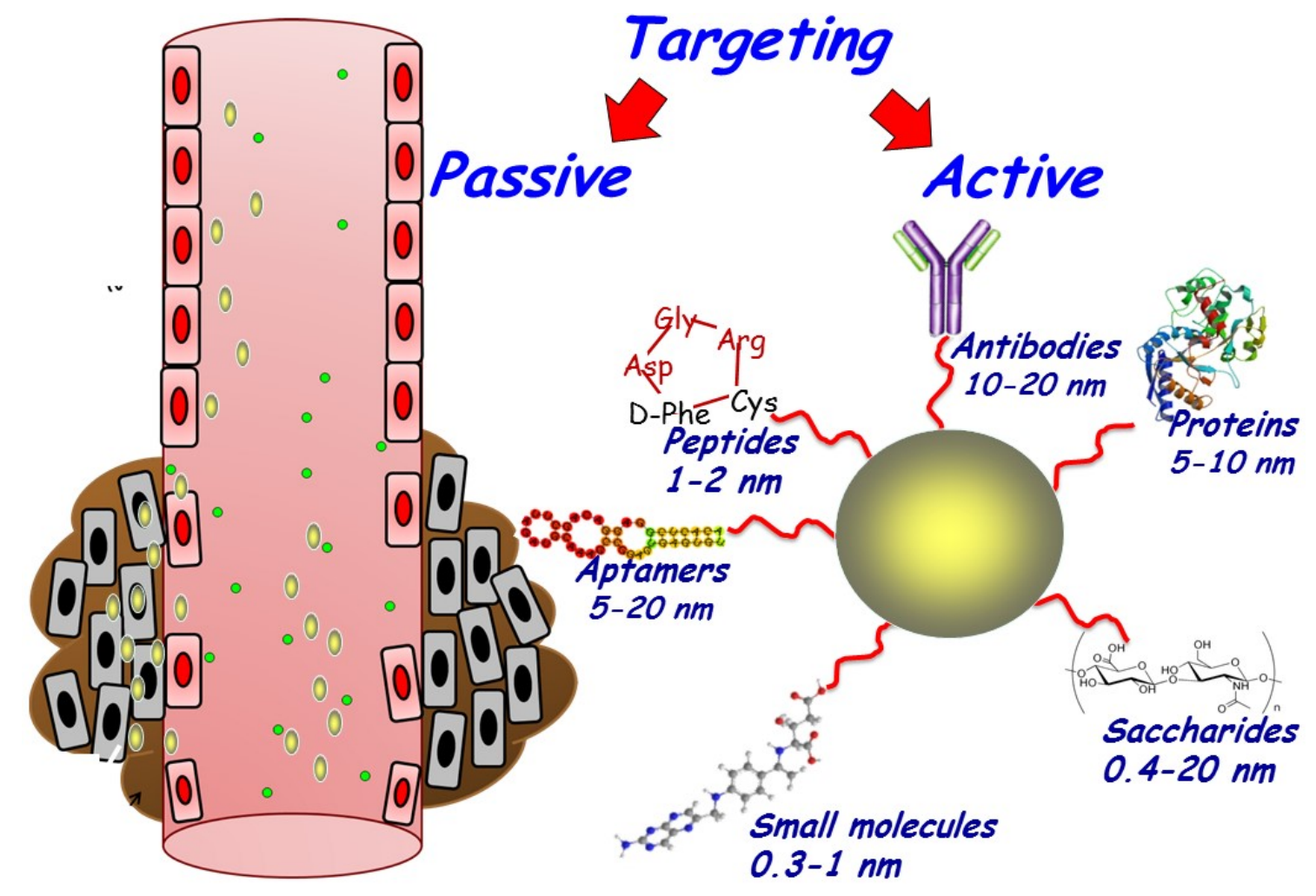

Figure 13. Sche matic re presentation of passive ta rgeting (left), where nanoparticles injected into the blood stream preferentially a ccumulate in solid tumours thanks to their particular blood vessel archiotectures; and active targeting (right) with nanoparticles decorated with different targeting moieties.

On the other hand, active targeting is based on the fact that some tumour cells overexpress certain receptors on their surface. If nanoparticles are functionalised with ligands with high affinity towards those receptors, the specific retention and uptake of those nanoparticles by cancer cells can be enhanced. This is of particular interest because tumour mass has been found to be a very heterogeneous tissue, composed of many different types of cells. Thus, it is necessary to provide nanoparticles the capacity to distinguish between tumour cells and the rest of the cells that might be present into the neoplastic tissue. There are many different approaches for decorating the surface of MSNs with certain ligands able to interact selectively with specific cellular receptors overexpressed in tumour cells. Some examples of targeting ligands grafted to MSNs are transferrin [36,58,59], epidermal growth factor [60], 
folic acid [61,62,63,64,65,66,67,68], methotrexate [69], anisamide [66], transactivator of transcription peptides [70,71,72], interleukin-13 peptide [73], anti-herceptin [74], antiepidermal growth factor receptor [75], anti-receptor tyrosine-protein kinase [76], metaaminobenzyl guanidine [77], RGD-type peptide [78,79,80,81,82], concanavalin A [83], cyclic RGD [84,85,86], anti-cell adhesion molecule 1 [87], and vascular endothelial growth factor [88]. However, the lack of application of those covalently targeted systems in the clinic might be explained by the fact that when placing MSNs in a biological environment, their surface would be rapidly covered by proteins, leading to the formation of a corona. The adsorption of those proteins would alter many surface properties of the nanoparticles, masking all the previous designed targeting moieties, and providing the nanoparticles with a totally new identity that would determine their biodistribution.

An additional problem when approaching the treatment of cancer with nanoparticles is the poor penetration of those nanoparticles across the tumour mass. This is due to the presence of collagen in the extracellular matrix of the tumour mass, which makes it denser than the matrices present in healthy tissues. That high density makes even more difficult for the nanoparticles to penetrate into the tumour mass. A possible approach to tackle this high density matrix was developed decorating the surface of MSNs with collagenase, which is a proteolyticenzyme capable of digesting the collagen rich extracellular matrix [89]. This enzyme was protected with $\mathrm{pH}$ sensitive polymeric capsules to avoid any type of biodegradation before reaching the tumour tissue. Thus, under the typical acidic environments of tumours, those nanocapsules would be decomposed, releasing the collagenase that would digest the extracellular matrix of the tumour, and therefore improving the penetrability of the MSNs deep into the tumour mass (Figure 14).

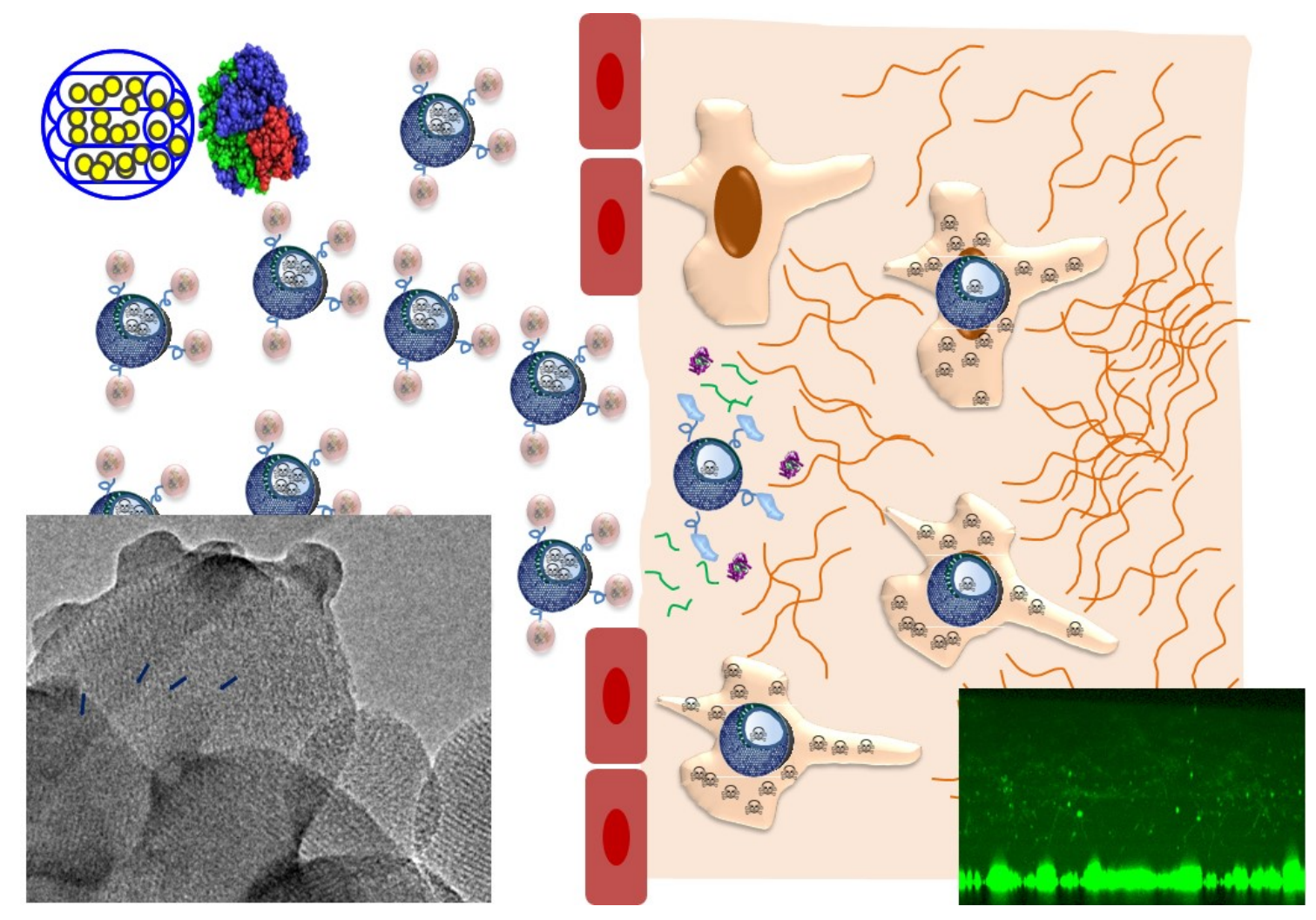

Figure 14. Sche matic re presentation of MSNs decorated with ca psules that contain collagenase. Once the capsules a re degraded, the collagenase would digest the collagen-rich extracellular matrix of the tumour. On the right hand bottom corner of the figure, a 3D collagen gel was prepared with HOS cells seeded, and the penetration of fluorescentlylabelled MSNs on the collagen gels was evaluated. [89] 
A totally different approach to selectively accumulate MSNs in tumours is based on using cells with migratory properties towards tumours as vehicles for those MSNs. In this sense, human Decidua Mesenchymal Stem Cells (DMSCs) have been successfully employed as carriers of nanopartciles. Those cells present very interesting characteristics, such as migration towards tumours both in vitro and in vivo, reducing the development of those tumours; they are very easy to obtain; and they represent a homogeneous population, being adult stem cells, which avoid any ethical concerns [90]. These DMSCs have been employed to ferry MSNs loaded with doxorubicin to tumour tissues [26]. The capability of those cells to migrate towards tumours both in vitro and in vivo was successfully evaluated, together with their ability to induce tumour cells death. Additionally, US responsive MSNs have also been internalised into those cells observing that MSNs were transported by the cells, and once in the tumour tissue, the application of US triggered the release of the cargo from the MSNs [91]. Thus, cellular transportation to specific tissues and responsive behaviour were combined at the same time (Figure 15), which represents a very promising platform to be used in the area of nanomedicine for the treatment of cancer.

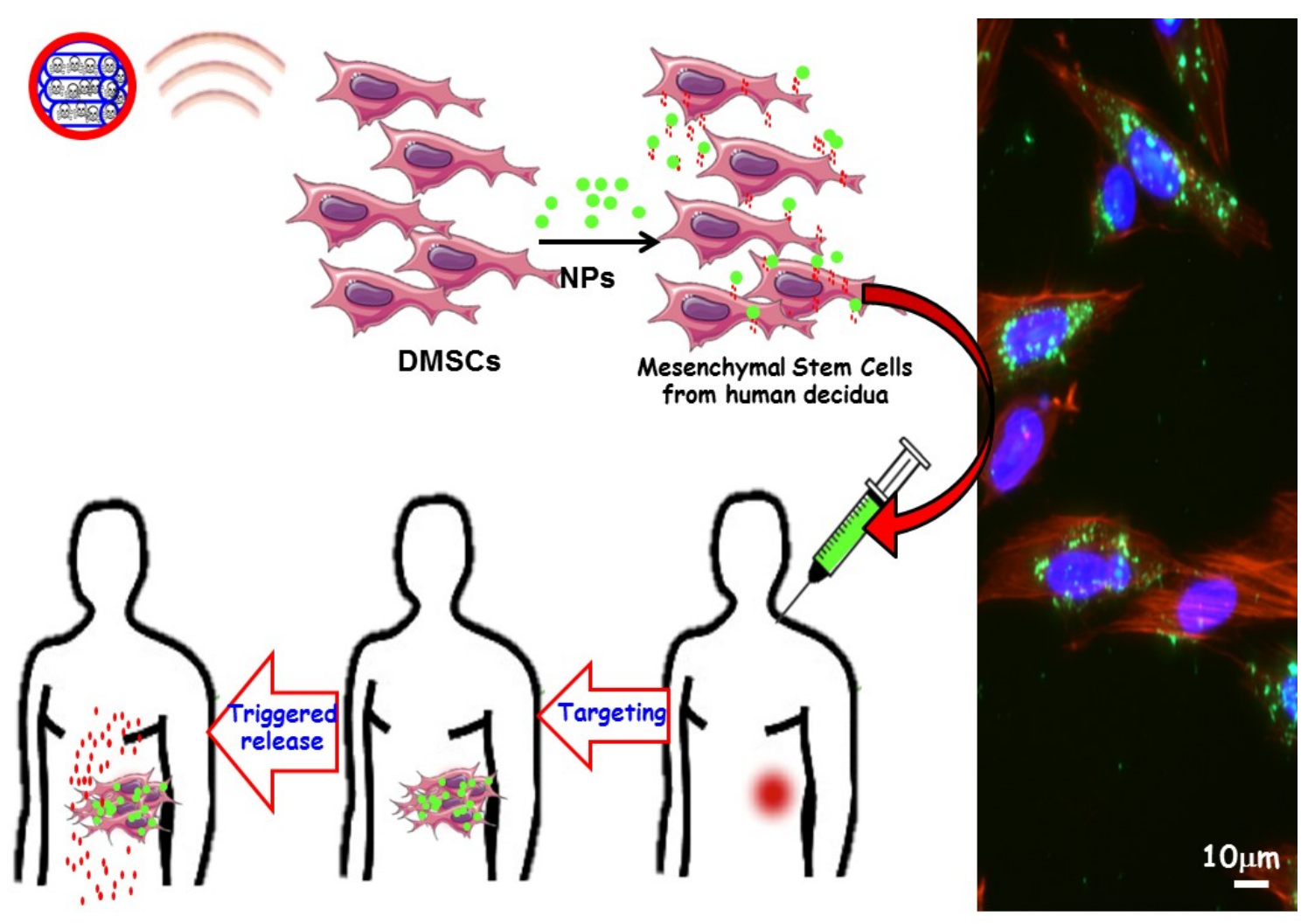

Figure 15. Schematic representation of DMSCs transporting US-sensitive MSNs towards tumour tissues.[91]

\section{Conclusions}

MSNs have become very promising nanocarriers to potentially treat cancer thanks to their outstanding properties, such as their great loading capacity, their easiness to be surface decorated, their robustness and their observed low toxicity. The possibility of designing smart nanocarriers able to respond to certain stimuli, both internal or external, and to selectively accumulate in determined pathological tissues have fuelled the interest of the nanomedicine community into those mesoporous silica materials. 
However, if translation to the clinic is aimed, it is necessary to present a proof of concept of efficacy and toxicity with those new approaches. After comparing the MSNs platforms with the standard of care, the potential advantages of those nanocarriers should be clearly shown employing pharmacokinetic and pharmacodynamics studies. Then, toxicity in real scenarios should be discarded to then ensure, through biodistribution studies, that MSNs reach tumour tissues. Thus, there are manypreclinical tests that should be successfully carried out before getting involved into clinical trials. The sooner those experiments might be done, the sooner we might find MSNs involved into clinical trials and, maybe in the future, into the Clinic.

\section{Acknowledgements}

This work was supported by the European Research Council, ERC-2015-AdG (VERDI), Proposal no. 694160 and Ministerio de Economía y Competitividad (MINECO) (MAT2015-64831-R grant).

\section{References}

\footnotetext{
${ }^{1}$ Webster TJ. Nanomedicine: what's in a definition?. Int J Nanomedicine. 2016; 1:115-6.

2 Min Y, Caster JM, Eblan MJ, Wang AZ. Clinical Translation of Nanomedicine. Chem Rev. 2015;115:11147-90.

${ }^{3}$ Shi J, Kantoff PW, Wooster R, Farokhzad OC. Cancer nanomedicine: progress, challenges and opportunities. Nat Rev Cancer. 2016;17:20-37.

${ }^{4}$ Ragelle H, Danhier F, Préat V, Langer R, Anderson DG. Nanoparticle-based drug delivery systems: a commercial and regulatory outl ook as the field matures. Expert Opin Drug Deliv. 2017;14: 851-64.

${ }^{5}$ Vallet-Regí M, Rámila A, Del Real RP, Pérez-Pariente J. A new property of MCM-41: drug delivery system. Chem Mater.2001;13(2):308-11.

${ }^{6}$ Manzano M, Vallet-Regí M. New developments in ordered mesoporous materials for drug delivery. J Mater Chem. 2010;20:5593-604.

${ }^{7}$ Manzano M, Colilla M, Vallet-Regí M. Drug delivery from ordered mesoporous matrices. Expert Opin Drug Deliv. 2009;6(12):1383-400.

${ }^{8}$ Baeza A, Manzano M, Colilla M, Vallet-Regí M. Recent advances in mesoporous silica nanoparticles for antitumor therapy: our contribution. Biomaterials science. 2016;4(5):803-13.

${ }^{9}$ Vallet-Regí M, Manzano M, González-Calbet JM, Okunishi E. Evidence of drug confinement into silica mesoporous matrices by STEM spherical aberration corrected microscopy. Chemical Communications. 2010;46(17):2956-8.

${ }^{10}$ Vallet-Regí M, Colilla M, González B. Medical applications of organic-inorganic hybrid materials within the field of silica-based bioceramics. Chem Soc Rev. 2011;40(2):596-607.

${ }^{11}$ Simmchen J, Baeza A, Ruiz D, Esplandiu MJ, Vallet-Regí M. Asymmetric hybrid silica nanomotors for capture and cargo transport: towards a novel motion-based DNA sensor. Small.2012;8(13):2053-9.
} 
${ }^{12}$ González B, Ruiz E, Feito MJ, Lopez C, Arcos D, Ramírez C, Matesanz C, Portolés MT, Vallet-Regí M. Covalently bonded dendrimer-maghemite nanosystems: nonviral vectors for in vitrogene magnetofection. J Mater Chem. 2011;21:4598-604

${ }^{13}$ Li Z, Barnes JC, Bosoy A, Stoddart JF, Zink JI. Mesoporous silica nanoparticles in biomedical applications. Chem Soc Rev. 2012;41:2590-605.

${ }^{14}$ Vallet-Regí M, Ruiz-Hernandez E. Bioceramics: from bone regeneration to cancer nanomedicine. Adv Mater. 2011;23:5177-218.

${ }^{15}$ Mamaeva V, Sahlgren C, Lindén M. Mesoporous silica nanoparticles in medicine:recent advances. Adv Drug Delivery Rev. 2013;65:689-702.

${ }^{16}$ Slowing I, Trewyn BG , Lin VSY. Effect of Surface Functionalization of MCM-41-Type Mesoporous Silica Nanoparticles on the Endocytosis by Human Cancer Cells. J Am Chem Soc. 2006;128:14792-3.

${ }^{17}$ Lu F, Wu SH, Hung Y, Mou CY. Size effect on cell uptake in well-suspended, uniform mesoporous silica nanoparticles. Small. 2009;5:1408-13.

${ }^{18}$ Trewyn BG, Nieweg JA, ZhaoY, Lin VSY. Biocompatible mesoporous silica nanoparticles with different morphologies for animal cell membrane penetration. Chem Eng J. 2008;137:23-9.

${ }^{19}$ Chen Y, Chen H, Shi J. In vivo bio-safety evaluations and diagnostic/therapeutic applications of

chemically designed mesoporous silica nanoparticles. Adv Mater. 2013;25:3144-76.

${ }^{20}$ Hudson SP, Padera RF, Langer R, Kohane DS. The biocompatibility of mesoporous silicates.

Biomaterials. 2008;29:4045-55.

${ }^{21}$ Lu J, Liong M, Li Z, Zink JI, Tamanoi F. Biocompatibility, biodistribution, and drug-delivery efficiency of mesoporous silica nanoparticles for cancer therapy in animals. Small. 2010;6:1794-805.

${ }^{22}$ Zhao Y, Sun X, Zhang G, Trewyn BG, Slowing II, Lin VSY. Interaction of mesoporous silica nanoparticles with human red blood cell membranes: sizeand surface effects. ACS Nano. 2011;5:1366-75.

23 Joglekar M, Roggers RA, Zhao Y, Trewyn BG. Interaction effects of mesoporous silica nanoparticles with different morphologies on human red blood cells. RSC Adv.2013;3:2454-61.

${ }^{24}$ Croissant JC, FatieievY, Almalik A, Khashab NM. Mesoporous Silica and Organosilica Nanoparticles: Physical Chemistry, Biosafety, Delivery Strategies, and Biomedical Applications. Adv Healthcare Mater. 2017:1700831.

${ }^{25}$ Pelaz B, Alexiou C, Alvarez-Puebla RA, Alves F, et al. Diverse Applications of Nanomedicine. ACS Nano. 2017;11:2313-81.

${ }^{26}$ Paris JL, de la Torre P, Manzano M, Cabañas MV, Flores Al, Vallet-Regí M. Decidua-derived mesenchymal stem cells as carriers of mesoporous silica na noparticles. In vitro and in vivo evaluation on mammary tumors. Acta biomaterialia. 2016;33:275-82.

${ }^{27}$ Nadrah P, Planinšek O, Gaberšček M. Stimulus-responsive mesoporous silica particles. J Mater Sci. 2014;49:481-495.

${ }^{28}$ Deng Y, Qi D, Deng C, Zhang X, ZhaoD. Superparamagnetic High-Magnetization Microspheres with an $\mathrm{Fe}_{3} \mathrm{O}_{4} @ \mathrm{SiO}_{2}$ Core and Perpendicularly Aligned Mesoporous $\mathrm{SiO}_{2}$ Shell for Removal of Microcystins. J Am Chem Soc. 2008;130:28-29.

${ }^{29}$ Zhao W, Gu J, Zhang L, Chen H, Shi J. Fabrication of Uniform Magnetic Nanocomposite Spheres with a Magnetic Core/Mesoporous Silica Shell Structure. J Am Chem Soc. 2005;127:8916-8917.

${ }^{30}$ Arcos D, Fal-Miyar V, Ruiz-Hernández E, García-Hernández M, Ruiz-González ML, González-Calbet J, Vallet-Regí M. Supramolecular mechanisms in the synthesis of mesoporous magnetic nanospheres for hyperthermia. J Mater Chem. 2012;22:64-72.

${ }^{31}$ Guisasola E, Baeza A, Talelli M, Arcos D, Moros M, de la Fuente JM, Vallet-Regí M. MagneticResponsive Release Controlled by Hot Spot Effect. Langmuir. 2015;31:12777-82.

32 Baeza A, Guisasola E, Ruiz-Hernández E, Vallet-Regí M. Magnetically Triggered Multidrug Release by Hybrid Mesoporous Silica Nanoparticles. Chem Mater. 201;24:517-24.

${ }^{33}$ Ruiz-Hernández E, Baeza A, Vallet-Regí M. Smart Drug Delivery through DNA/Magnetic Nanoparticle Gates. ACS Nano. 2011;5(2):1259-66.

${ }^{34}$ Giri S, Trewyn BG, Stellmaker MP, Lin VSY. Stimuli-responsive controlled-release delivery system based on mesoporous silica nanorods capped with magnetic nanoparticles. Angew Chemie - Int Ed. 2005;44:5038-5044.

${ }^{35}$ Mal NK, Fujiwara M, Tanaka Y. Photocontrolled reversible rel ease of guest molecules from coumarinmodified mesoporous silica. Nature. 2003;421:350-3. 
${ }^{36}$ Martínez-Carmona M, Baeza A, Rodriguez-Milla MA, García-Castro J, Vallet-Regí M. Mesoporous silica nanoparticles grafted with a light-res ponsive protein shell for highly cytotoxic antitumoral therapy.J Mater Chem B. 2015;3:5746-52.

${ }^{37}$ Martínez-Carmona M, Lozano D, Baeza A, Colilla M, Vallet-Regí M. A novel visiblelight responsive nanosystem for cancer treatment. Nanoscale. 2017;9:15967-73.

${ }^{38}$ Paris JL, Cabañas MV, Manzano M, Vallet-Regí M. Polymer-Grafted Mesoporous Silica Nanoparticles as Ultrasound-Responsive Drug Carriers. ACS Nano. 2015;9:11023-33.

${ }^{39}$ Anirudhan TS, Nair AS. Temperature and Ultrasound Sensitive Gatekeepers for the Controlled Release of Chemotherapeutic Drugs from Mesoporous Silica Nanoparticles. J Mater Chem B. 2018;6:428-439.

${ }^{40}$ Wang $X$, Chen $H$, Zheng Y, Ma M, Chen Y, Zhang K, Zeng D, Shi J. Au-nanoparticle coated mesoporous silica na noca psule-based multifunctional platform for ul trasound mediated imaging, cytoclasis and tumor ablation. Biomaterials. 2013;34:2057-2068.

${ }^{41}$ Liu R, Zhang Y, Zhao X, Agarwal A, Mueller L, Feng P. pH-responsivenanogated ensemble based on gold-capped mesoporous silica through an acid-labile acetal linker. J Am Chem Soc. 2010;132:1500-1.

${ }^{42}$ Gan Q, Lu X, Yuan Y, Qian J, Zhou H, Lu X, Shi J, Liu C. A magnetic, reversiblepH-responsivenanogated ensemble based on Fe3O4 nanoparticles-capped mesoporous silica. Biomaterials. 2011;32:1932-42.

${ }^{43}$ Xu C, Lin Y, Wang J, Wu L, Wei W, Ren J, Qu X. Nanoceria-triggered synergetic drug release based on $\mathrm{CeO} 2$-capped mesoporous silica host-guest interactions and switchable enzymatic activity and cellular effects of CeO2. Adv Healthc Mater. 2013;2:1591-9.

${ }^{44}$ Feng W, Zhou X, He C, Qiu K, Nie W, Chen L, Wang H, Mo X, Zhang Y. Polyelectrolyte multilayer functionalized mesoporous silica nanoparticles for $\mathrm{pH}$-responsive drug delivery: Layer thicknessdependent release profiles and biocompatibility.J Mater Chem B. 2013;1:5886-98.

${ }^{45}$ Meng H, Xue M, Xia T, Zhao YL, Tamanoi F, Stoddart JF, Zink JI, Nel AE. Autonomous in vitro anticancer drug release from mesoporous silica nanoparticles by $\mathrm{pH}$-sensitive nanovalves. J Am Chem Soc. 2010;132:12690-7.

${ }^{46}$ Gao Y, Yang C, Liu X, Ma R, Kong D, Shi L. A multifunctional nanocarrier based on nanogated mesoporous silica for enhanced tumor-specific uptake and intracellular delivery. Macromol Biosci. 2012;12:251-9.

${ }^{47}$ Rim HP, Min KH, Lee HJ, Jeong SY, Lee SC. pH-tunable calcium phosphatecovered mesoporous silica nanocontainers for intracellular controlled rel ease of guest drugs. Angew Chem Int Ed. 2011;50:8853-7.

${ }^{48}$ Martínez-Carmona M, Lozano D, Colilla M, Vallet-Regí M. Selective topotecan delivery to cancer cells by targeted pH-sensitive mesoporous silica nanoparticles. RSC Adv. 2016;6:50923-32.

${ }^{49}$ Gisbert-Garzarán M, Lozano D, Vallet-Regí M, Manzano M. Self-immolative polymers as novel pHresponsive gatekeepers for drug delivery. RSC Adv. 2017;7:132-6.

${ }^{50}$ Yuan L, Tang Q, Yang D, Zhang JZ, Zhang F, Hu J. Preparation of pH-Responsive Mesoporous Silica Nanoparticles and Their Application in Controlled Drug Delivery. J Phys Chem C. 2011;115:9926-9932.

${ }^{51}$ Chang B, Sha X, Guo J, Jiao Y., Wang C, Yang W. Thermo and pH dual responsive, polymer shell coated, magnetic mesoporous silica nanoparticles for controlled drug release. J Mater Chem. 2011;21:9239.

52 Li Z, Clemens DL, Lee B-Y, Dillon BJ, Horwitz MA, ZinkJI. Mesoporous Silica Nanoparticles with pHSensitive Nanovalves for Delivery of Moxifloxacin Provide Improved Treatment of Lethal Pneumonic Tularemia. ACS Nano. 2015;9:10778-10789.

${ }^{53}$ Bildstein L, Dubernet C, Couvreur P. Prodrug-based intracellular delivery of anticancer agents. Adv Drug Delivery Rev. 2011;63:3-23.

${ }^{54}$ Baeza A, Guisasola E,Torres-Pardo A, González-Calbet JM, Melen GJ, Ramírez M, Vallet-Regí M. Hybrid enzyme-polymeric capsules/mesoporous silica nanodevice for in situ cytotoxic agent generation. Adv Funct Mater. 2014;24:4625-33.

${ }^{55}$ Zhang W, Shen J, Su H, Mu G, Sun J-H, Tan C-P, Liang XJ, Ji L-N, Mao Z-W. Co-Delivery of Cisplatin Prodrug and Chlorin e6 by Mesoporous Silica Nanoparticles for Chemo-Photodynamic Combination Therapy to Combat Drug Resistance. ACS Appl Mater Interfaces. 2016;8:13332-13340.

${ }^{56}$ Matsumura Y, Maeda H., A new concept for macromolecular therapeutics in cancer chemotherapy: mechanism of tumoritropic accumulation of proteins and the antitumor agent smancs. Cancer Res. 1986;46:6387-92.

${ }^{57}$ Nakamura H, Fang J, Maeda H. Development of next-generation macromolecular drugs based on the EPR effect: challenges and pitfalls. Expert Opin Drug Delivery. 2015;12:53-64. 
${ }^{58}$ Ferris DP, Lu J, Gothard C, Yanes R, Thomas CR, Olsen JC, Stoddart JF, Tamanoi F, Zink JI. Synthesis of biomolecule-modified mesoporous silica nanoparticles for targeted hydrophobic drug delivery to cancer cells. Small. 2011;7:1816-26.

${ }^{59}$ Fang W, Wang Z, Zong S, Chen H, Zhu D, Zhong Y, Cui Y. pH-controllabledrug carrier with SERS activity for targeting cancer cells. Biosens Bioelectron. 2014;57:10-5.

${ }^{60}$ Mickler FM, Moeckl L, Ruthardt N, Ogris M, Wagner E, Braeuchle C. Tuning nanoparticle uptake: Livecell imaging reveals two distinct endocytosis mechanisms mediated by natural and artificial EGFR targeting ligand. Nano Lett. 2012;12:3417-23.

${ }^{61}$ Rosenholm JM, Meinander A, Peuhu E, Niemi R, Eriksson JE, Sahlgren C, Linden M. Targeting of porous hybrid silica nanoparticles to Cancer Cells. ACS Nano. 2009;3:197-206.

${ }^{62}$ Lu J, Li Z, Zink JI, Tamanoi F. In vivo tumor suppression efficacy of mesoporous silica nanoparticlesbased drug-delivery system: Enhanced efficacy by folate modification. Nanomedicine. 2012;8:212-20.

${ }^{63}$ Wang LS, Wu LC, Lu SY, Chang LL, Teng IT, Yang CM, Ho JAA. Bi ofunctionalized phospholipid-capped mesoporous silica nanoshuttles for targeted drug delivery: Improved water suspensibility and decreased nonspecific protein binding. ACS Nano. 2010;4:4371-9.

${ }^{64}$ Slowing I, Trewyn BG, Lin VSY. Effect of surface functionalization of MCM-41-type mesoporous silica nanoparticles on the endocytosis by human cancer cells. J Am Chem Soc. 2006;128:14792-3.

${ }^{65}$ Porta F, Lamers GEM, Morrhayim J, Chatzopoulou A, Schaaf M, den Dulk H, Backendorf C, Zink JI, Kros A. Folic acid-modified mesoporous silica nanoparticles for cellular and nuclear ta rgeted drug delivery. Adv Healthc Mater. 2013;2:281-6.

${ }^{66}$ Vivero-Escoto JL, Taylor-Pashow KML, Huxford RC, Della Rocca J, Okoruwa C, An H, Lin W, Lin W. Multifunctional mesoporous silica nanospheres with cleavable Gd(III) chelates as MRI contrast agents: Synthesis, characterization, target-s pecificity, and renal clearance. Small. 2011;7:3519-28.

${ }^{67}$ Martínez-Carmona M, Lozano D, Colilla M, Vallet-Regí M. Selective topotecan delivery to cancer cells by targeted pH-sensitive mesoporous silica nanoparticles. RSC Adv. 2016;6:50923-32.

${ }^{68}$ López V, Villegas MR, Rodríguez V, Villaverde G, Lozano D, Baeza A, Vallet-Regí M. Janus Mesoporous Silica Nanoparticles for Dual Targeting of Tumor Cells and Mitochondria. ACS Appl Mater Interfaces. 2017;9:26697-706.

69 Rosenholm JM, Peuhu E, Bate-Eya LT, Eriksson JE, Sahlgren C, Linden M. Cancer-cell-specific induction of apoptosis using mesoporous silica nanoparticles as drug-delivery vectors. Small. 2010;6:1234-41.

${ }^{70}$ Pan L, He Q, LiuJ, Chen Y, Ma M, Zhang L, Shi J. Nuclear-targeted drug delivery of TAT peptideconjugated monodisperse mesoporous silica nanoparticles. J Am Chem Soc. 2012:134;5722-5.

${ }^{71}$ Li Z, Dong K, Huang S, Ju E, Liu Z, Yin M, Ren J, Qu X. A smart nanoassembly for multistage targeted drug delivery and magnetic resonance imaging. Adv Funct Mater. 2014;24:3612-20.

72 Pan L, Liu J, He Q, Wang L, Shi J. Overcoming multidrug resistance of cancer cells by direct intranuclear drug delivery using TAT-conjugated mesoporous silica na noparticles. Biomaterials. 2013;34:2719-30.

${ }^{73}$ Wang Y, Wang K, Zhao J, Liu X, Bu J, Yan X, Huang R. Multifunctional mesoporous silica-coated graphene nanosheet used for chemo-photothermal synergistic targeted therapy of glioma.J Am Chem Soc. 2013:135;4799-804.

74 Milgroom A, Intrator M, Madhavan K, Mazzaro L, Shandas R, Liu B, Park D. Mesoporous silica nanoparticles as a breast-cancer targeting ul trasound contrast agent. Colloids Surfaces B. 2014;116:6527.

${ }^{75}$ Tsai CP, Chen CY, Hung Y, Chang FH, Mou CY. Monoclonal antibody-functionalized mesoporous silica nanoparticles (MSN) for sel ective targeting breast cancer cells. J Mater Chem. 2009;19:5737-43.

${ }^{76}$ Deng Z, Zhen Z, Hu X, Wu S, Xu Z, Chu PK. Hollow chitosan-silica nanospheres as pH-sensitive targeted delivery carriers in breast cancer therapy. Biomaterials. 2011;32:4976-86.

${ }^{77}$ Villaverde G, Baeza A, Melen GJ, Alfranca A, Ramírez M, Vallet-Regí M. A new targeting agent for the selective drug delivery of nanocarriers for treating neuroblastoma.J Mater Chem B. 2015;3:4831-42.

${ }^{78}$ Villaverde G, Nairi V, Baeza A, Vallet-Regí M. Double sequential encrypted targeting sequence: A new concept for bone cancer treatment. Chem Eur J. 2017;23:7174-9.

${ }^{79}$ Luo GF, Chen WH, Liu Y, Zhang J, Cheng SX, Zhuo RX, Zhang XZ. Charge-reversal plug gate nanovalves on peptide-functionalized mesoporous silica nanoparticles for targeted drug delivery.J Mater Chem $B$.

2013;1:5723-32.

${ }^{80}$ Zhang J, Yuan ZF, Wang Y, Chen WH, Luo GF, Cheng SX, Zhuo RX, Zhang XZ. Multifunctional envelopetype mesoporous silica nanoparticles for tumor-triggered targeting drug delivery. J Am Chem Soc.

2013;135:5068-73. 
${ }^{81}$ Xiao D, Jia HZ, Zhang J, Liu CW, Zhuo RX, Zhang XZ. A dual-responsive mesoporous silica na noparticle for tumor-triggered targeting drug delivery. Small. 2014;10:591-8.

82 He L, Huang Y, Zhu H, Pang G, Zheng W, Wong YS, Chen T. Cancer-targeted monodisperse mesoporous silica nanoparticles as carrier of ruthenium polypyridyl complexes to enhance theranostic effects. Adv Funct Mater. 2014;24:2754-63.

${ }^{83}$ Martínez-Carmona M, Lozano D, Colilla M, Vallet-Regí M. Lectin-conjugated pH-responsive mesoporous silica nanoparticles for targeted bone cancer treatment. Acta Biomater. 2017;65:393-404. ${ }^{84}$ Cheng SH, Lee CH, Chen MC, Souris JS, Tseng FG, Yang CS, Mou CY, Chen CT, Lo LW. Tri-

functionalization of mesoporous silica nanoparticles for comprehensive cancer theranostics-the trio of imaging, targeting and therapy. J Mater Chem. 2010;20:6149-57.

${ }^{85}$ Huang DM, Chung TH, Hung Y, Lu F, Wu SH, Mou CY, Yao M, Chen YC. Toxicol. Internalization of mesoporous silica nanoparticles induces transient but not sufficient osteogenic signals in human mesenchymal stem cells. Appl Pharmacol. 2008;231:208-15.

${ }^{86}$ Fang IJ, Slowing II, Wu KCW, Lin VSY, Trewyn BG. Ligand conformation dictates membrane and endosomal trafficking of arginine-glycine-aspartate (RGD)-functionalized mesoporous silica nanoparticles. Chemistry. 2012;18:7787-92.

${ }^{87}$ Yang H, Zhao F, Li Y, Xu M, Li L, Wu C, Miyoshi H, Liu Y. VCAM-1-targeted core/shell nanoparticles for selective adhesion and delivery to endothelial cells with lipopolysaccharide-induced inflammation under shear flow and cellular magnetic resonance imaging in vitro. Int J Nanomed. 2013;8:1897-906.

${ }^{88}$ Goel S, Chen F, Hong H, Valdovinos HF, Hernandez R, Shi S, Barnhart TE, Cai W. VEGF(121)-Conjugated Mesoporous Silica Nanoparticle: A Tumor Targeted Drug Delivery System. ACS Appl Mater Interfaces. 2014;6:21677-85.

${ }^{89}$ Villegas MR, Baeza A, Vallet-Regí M. Hybrid Collagenase Nanocapsules for Enhanced Nanocarrier Penetration in Tumoral Tissues. ACS Appl Mater Interfaces. 2015;7:24075-81.

${ }^{90}$ Vegh I, Grau M, Gracia M, Grande J, de la Torre P, Flores Al. Decidua mesenchymal stem cells migrated toward mammary tumors in vitro and in vivo affecting tumor growth and tumor development. Cancer Gene Ther. 2013;20:8-16.

${ }^{91}$ Paris JL, de la Torre P, Cabañas MV, Manzano M, Grau M, Flores Al, Vallet-Regí M. Vectorization of ultrasound-responsive nanoparticles in placental mes enchymal stem cells for cancer therapy. Nanoscale. 2017;4:5528-37. 